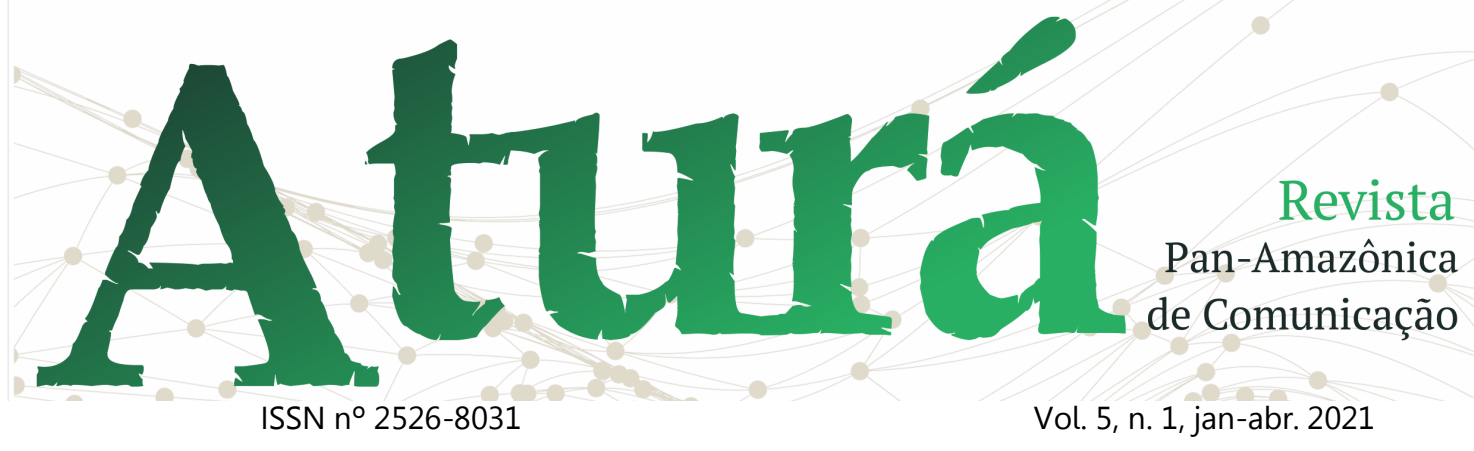

\title{
VAI TER PAI COM VAGINA SIM! DA (TRANS)PARENTALIDADE À TRANSFOBIA NA REPRESENTAÇÃO MASCULINA DE THAMMY MIRANDA EM UMA PROPAGANDA DE DIA DOS PAIS
}

Yes, we have a father with vagina! From (Trans) Parenting to Transphobia in Thammy Miranda's Male Representation in a Father's Day Advertisement

¡Sí! Tendremos un padre con vagina: De la (trans) paternidad a la transfobia en la representación masculina de Thammy Miranda en un anuncio de Día del Padre

\section{Raphaella Freitas Petkovic de Carvalho Pereira, Universidade Paulista/SP 1}

\section{RESUMO}

Ultimamente, o Brasil tem vivenciado um notório aumento no número de famílias compostas por pais LGBTQI+. Essas famílias são estigmatizadas pela sociedade, muitas vezes preconceituosa e heteronormativa, demonstrando uma grande necessidade de mudança de pensamentos e convicções sociais. Tomamos por base o anúncio na mídia digital da campanha de Dia dos Pais "\#meupaipresente", em julho, pela empresa de cosméticos Natura, tendo como uma das estrelas o empresário Thammy Miranda, um pai transgênero. A propaganda movimentou as redes sociais e provocou as mais diversas reações na mídia, desde apoio até comentários transfóbicos e pedidos de boicote à marca pela não concordância em Thammy representar a figura paterna, utilizando-se majoritariamente da questão biológica como argumento. Considerando que os conteúdos simbólicos são úteis para as transformações sociais, historicizando as questões atuais, desnaturalizando o preconceito e afastando a discriminação (Spink e Medrado, 2004) e que o gênero é uma construção social e não biológica (Butler, 1991), as conclusões deste artigo apontam que a existência de diversos núcleos familiares, inclusive com transgêneros

\footnotetext{
${ }^{1}$ Discente do Curso Aperfeiçoamento de Oficiais da Polícia Militar do Estado do Tocantins, Capitão do Quadro de Oficiais Policiais Militares; Pós-graduado em Docência do Ensino Superior (2014); Pós-graduado em Direito Público: Constitucional, Administrativo e Tributário (2010); Bacharel em Segurança Pública pela Academia Policial Militar Tiradentes - APMT desde (2008); Bacharel em Direito (2009); e-mail: psaj83@gmail.com;
} 


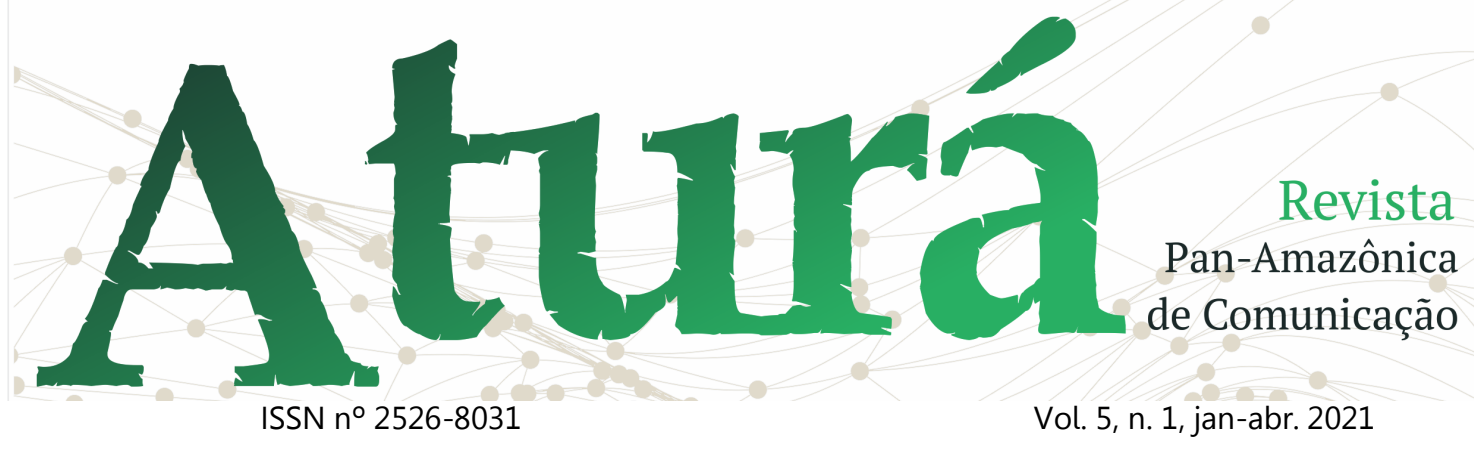

- ou (trans)parentais - são uma realidade no Brasil, devendo ser representados e legitimados, inclusive midiaticamente, sem tomar por base estereótipos e preconceitos.

PALAVRAS-CHAVE: Mídia Digital; Transgêneros; Preconceito de Gênero.

\begin{abstract}
Lately, Brazil has experienced a notable increase in the number of families composed of LGBTQI+ parents. These families are stigmatized by society, often prejudiced and heteronormative, demonstrating a great need to change social thoughts and convictions. We took as a basis the announcement in digital media of Father's Day campaign "\#meupaipresente", in July, by cosmetics' company Natura, having as a star the businessman Thammy Miranda, a transgender father. The propaganda moved social networks and provoked the most diverse reactions in the media, from support to transphobic comments and requests to boycott the brand for the disagreement in Thammy representing the father figure, using mostly the biological issue as an argument. Considering that symbolic contents are useful for social transformations, historicizing current issues, denaturalizing prejudice and removing discrimination (Spink and Medrado, 2004) and that gender is a social - and not biological - construction (Butler, 1991), the conclusions of this article point out that the existence of several family nuclei, including with transgender - or (trans) parental - are a reality in Brazil, and should be represented and legitimized, including media, without taking stereotypes and prejudices as a basis.
\end{abstract}

KEYWORDS: Digital Media; Transgenders; Gender Prejudice.

\title{
RESUMEN
}

Últimamente, Brasil ha experimentado un aumento notable en el número de familias compuestas por padres LGBTQI +. Estas familias son estigmatizadas por la sociedad, a menudo prejuiciosas y heteronormativas, lo que demuestra gran necesidad de cambiar los pensamientos y convicciones sociales. Tomamos como base el anuncio en medios digitales de la campaña del Día del Padre "\#meupaipresente", en julio, de la empresa de cosméticos Natura, teniendo como una de las estrellas al empresario Thammy Miranda, un padre transgénero. La propaganda movió las redes sociales y provocó las más diversas reacciones en los medios, desde apoyos a comentarios transfóbicos y boicots a la marca por el no acuerdo en Thammy para representar a la figura paterna, utilizando mayoritariamente la cuestión biológica como argumento. Considerando que los contenidos simbólicos son útiles para las transformaciones sociales, historizando temas de actualidad, desnaturalizando prejuicios y eliminando la discriminación (Spink y Medrado, 2004) y que el género es una construcción social y no biológica (Butler, 1991), las conclusiones de este artículo señalan que la existencia de varios núcleos familiares, incluso 


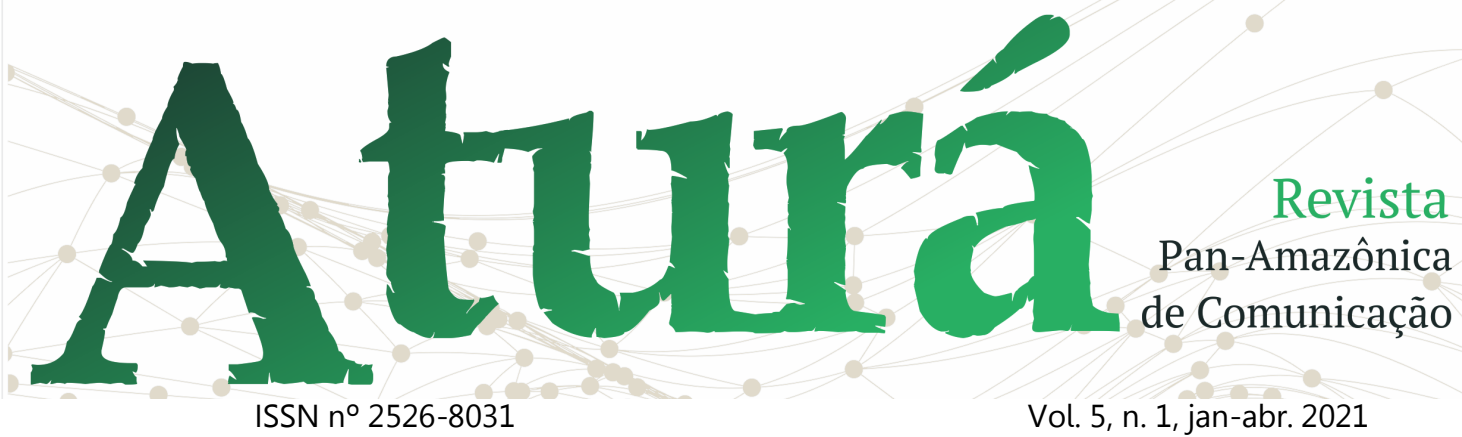

con transgénero - o (trans) parental - son una realidad en Brasil, y deben ser representados y legitimados, incluidos los medios, sin tomar como base estereotipos y prejuicios.

PALABRAS CLAVE: Medios Digitales; Transgéneros; Prejuicios de Género. 


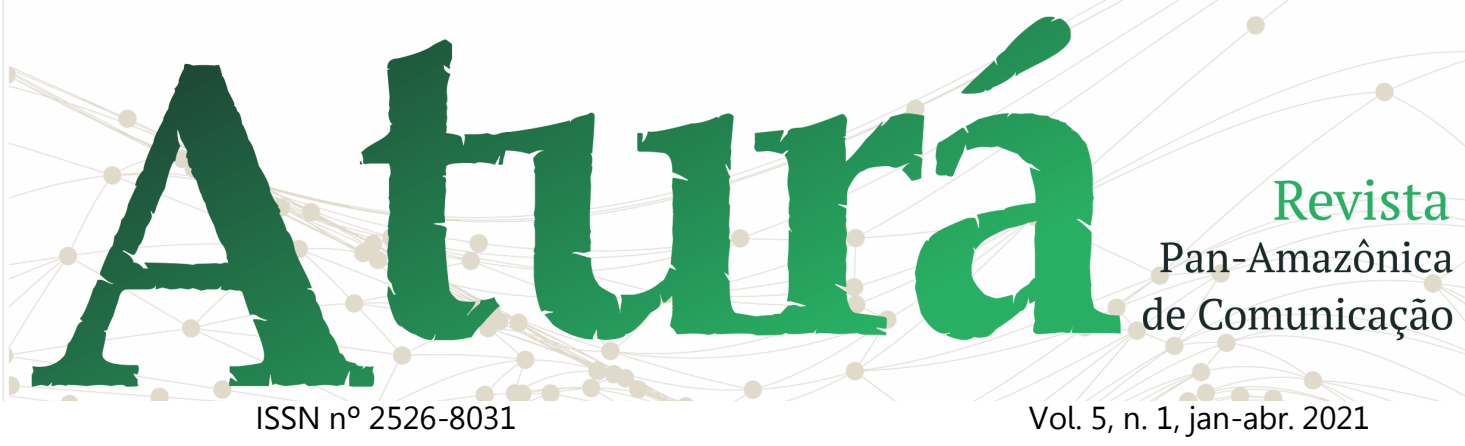

\section{Introdução}

As pessoas transgêneras são vítimas e protagonistas de estigmas e violências provenientes da cultura patriarcal e heteronormativa que fica cada dia mais evidente em nosso país. Não obstante, o Brasil é o país que mais mata pessoas trans no mundo, segundo pesquisa da organização não governamental Transgender Europe (TGEU), rede europeia de organizações que apoiam os direitos da população transgênero. Somando-se a isso, essas pessoas são excluídas do convívio social, dos locais de ensino, do mercado de trabalho e dos serviços de saúde, tendo seus direitos enquanto cidadãos negados por completo. (BRASIL, 2015)

Por anos, as pessoas trans foram consideradas "doentes" pela medicina, quadro que mudou apenas recentemente, no ano de 2018, com a despatologização da transexualidade ao ser retirada como transtorno mental na nova edição da Classificação Internacional de Doenças (CID-11). Conforme mencionado por
Pereira (2020), o movimento trans tem se organizado de forma a reivindicar sua identidade de gênero. Isso surge como uma forma de desvincular-se dos homossexuais, uma vez que a sigla LGBTIQ+ os integra e a sociedade em geral, durante muitos anos, acabou confundindo os conceitos de orientação sexual (gênero pelo qual a pessoa sente atração) e identidade de gênero (gênero com o qual a pessoa se identifica). Isso serve, conforme mencionado por Butler (2011, p. 20) para demonstrar que:

o gênero nem sempre se constituiu de
maneira coerente ou consistente nos
diferentes 'contextos históricos',
estabelecendo intersecções com
modalidades raciais, classistas, étnicas,
sexuais e regionais de identidades
discursivamente constituídas.

Quando falamos de transgêneros, falamos em tornar visível aquilo que é invisível. É incrível a invisibilidade a que estão sujeitos os que se identificam como trans e os raros estudos na academia brasileira sobre o tema da transgeneridade. Essas vozes foram silenciadas em diversos momentos de 


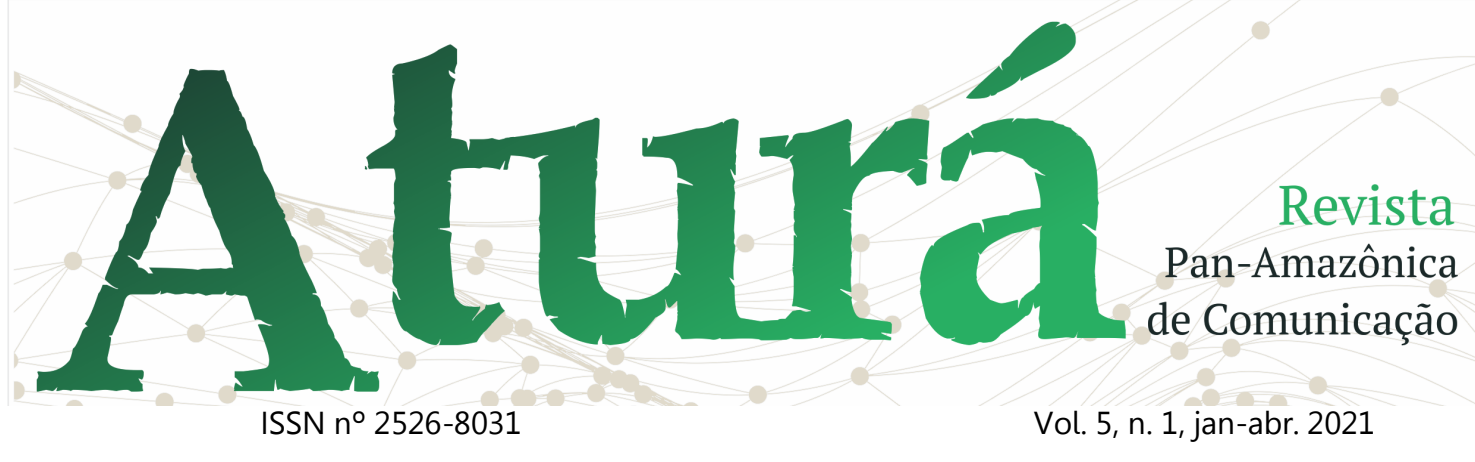

nossa história e muitas vezes associadas à marginalidade e deslegitimadas.

Para Castro (2016, p. 153), as pessoas trans "renunciam a estabilidade dos campos da normalidade para surgir como potência de emergência".

Sobre as famílias compostas por transgêneros ou por homossexuais, por exemplo, percebemos que o Brasil tem vivenciado um notório aumento no número de famílias compostas por pais LGBTQI+. Essas famílias são estigmatizadas pela sociedade, muitas vezes preconceituosa e heteronormativa, demonstrando uma grande necessidade de mudança de pensamentos e convicções sociais. Guimarães (2004, p. 40) complementa ao expor os papéis sociais esperados de um homem e uma mulher:

O processo de produção da sexualidade masculina - e da feminina, por contraste e oposição - é pautada por papéis sociais e papéis de gênero, que se constituem em modelos ideais de comportamento e atitude para cada sexo.

\section{As "Novas" Parentalidades}

Tomando por base o direito, mais especificamente no artigo 226 da Constituição Federal de 1988, temos que "a família é a base da sociedade tendo, portanto, especial proteção do Estado". Portilho e Rezende (2008) ressaltam que a CF/88 admite expressamente três modelos de família:

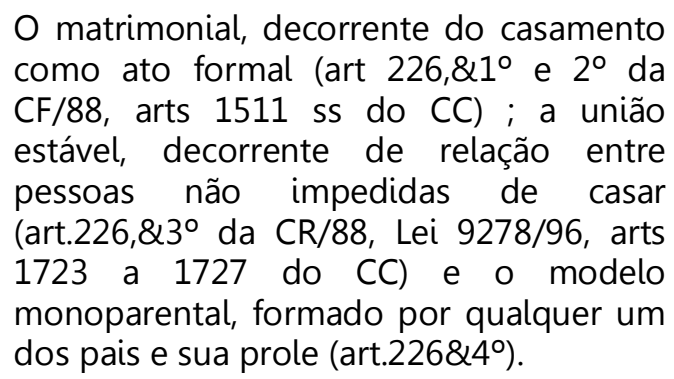

Importante mencionar que esses três tipos de família podem ser exercidos por pessoas de gênero e sexo iguais e/ou diferentes. Acerca disso, Dias (2006, p.25) menciona:

A entidade familiar está disposta em uma
estruturação psíquica em que cada um
ocupa um lugar e possui uma função (pai,
mãe e filho) sem, no entanto, estarem
ligados por laços consanguíneos. Assim,
há uma diversidade de modelos de família
como nos exemplos em que dois irmãos
vivem juntos, avós que cuidam de netos
como pais e relações homoafetivas
estáveis. Ou seja, com as diretrizes da Constituição Federal de 1988, a família 


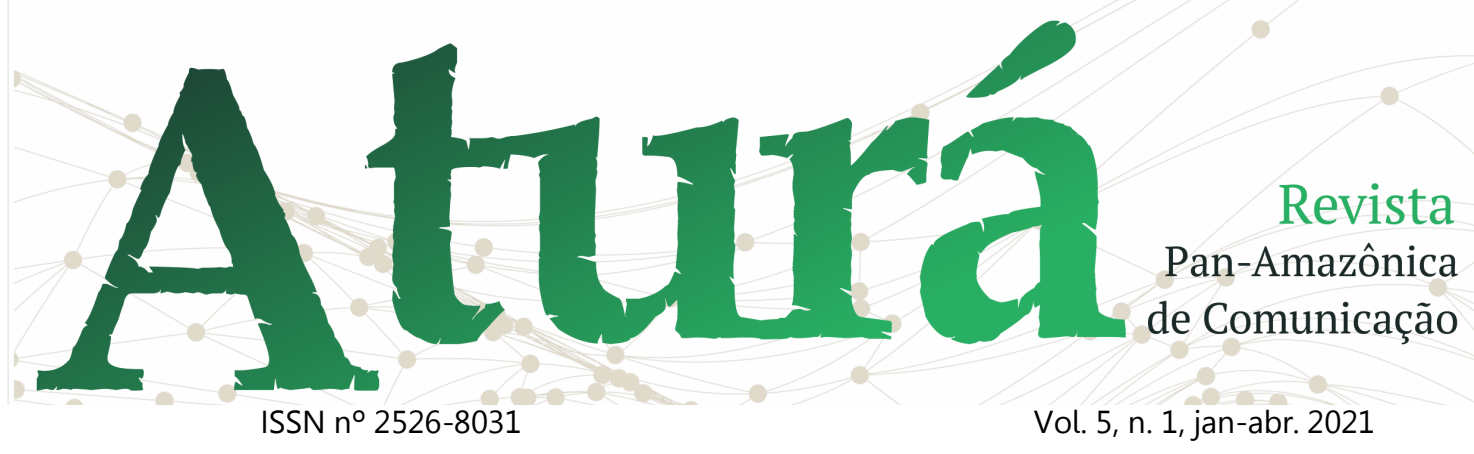

passa a ser considerada como "família plural", considerando principalmente o caráter socioafetivo das relações. Portilho e Rezende (2008) complementam dizendo que:

Em outras palavras, além da família matrimonial, a CR/88 reconheceu a existência de outros tipos familiares. Vale lembrar que é um rol exemplificativo de modelos de família. A doutrina e a jurisprudência aumentam tal rol, destacando-se a [...] família homoafetiva.

Zambrando (2006) aponta a necessidade da mudança de paradigmas sociais com o surgimento de novas configurações familiares. Para ela, "a emergência de famílias constituídas por pais/mães homossexuais, travestis e transgêneros no campo social torna obrigatório o enfrentamento de novas demandas e a desconstrução de velhas certezas". Ela ainda menciona o modelo também conhecido como "família ocidental":

No Ocidente, o modelo familiar mais comum corresponde ao da "família nuclear": um pai, uma mãe e filhos. Ele está apoiado em uma realidade biológica irredutivel até esse momento: é necessário um homem e uma mulher para produzir uma criança. Como consequência, a família nuclear procriativa

parece se impor como uma verdade incontestável, justamente por estar socialmente de acordo com o fato biológico.

Ao analisarmos alguns estudos históricos e antropológicos (Ariés, 1981; Donzelot, 1986), percebemos que a configuração de "família" vem sofrendo diversas mudanças com o passar dos anos, sendo um núcleo no qual predomina a afetividade.

Zambrano (2006) aponta que a "naturalização desse modelo de família torna-o incontestável e leva ao pensamento, comum na nossa cultura, de que uma criança pode ter apenas um pai e uma mãe, juntando na mesma pessoa o fato biológico da procriação, o parentesco, a filiação e os cuidados de criação.". segundo ela, isso ocorre pois, quando percebemos "pai" e "mãe" apenas como aqueles que dão a vida à criança, concebemos essa relação como tão "natural" que nem pensamos possa ser ela submetida à lei social.

Lévi-Strauss (1976) também relata que a família não é uma entidade em si, mas sim, o lugar onde se desenvolvem as 


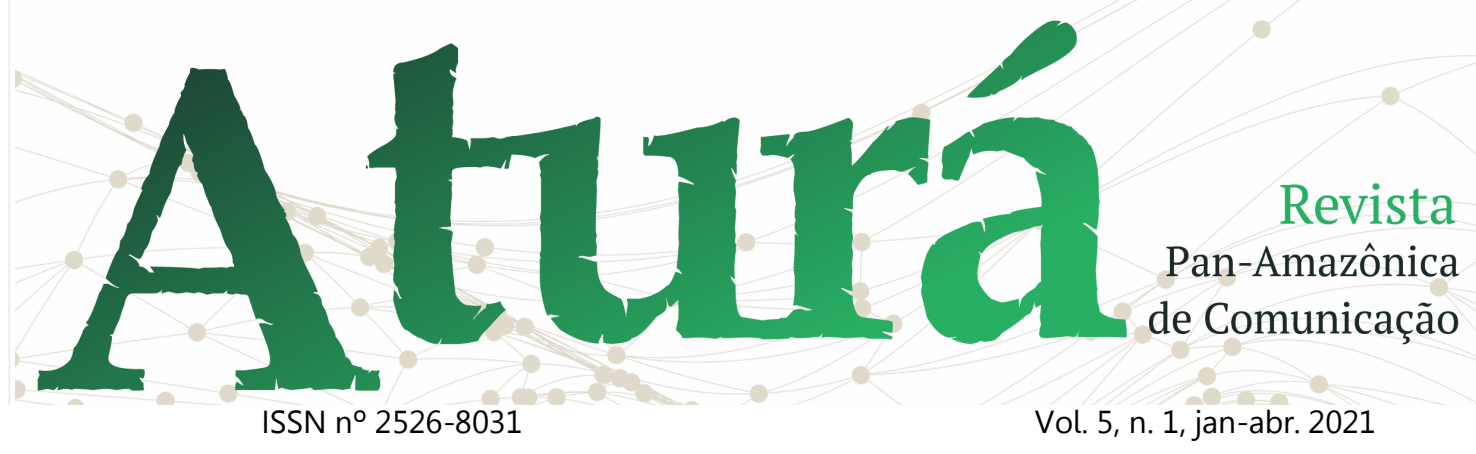

normas de filiação e de parentesco, que acabam por construir sistemas elementares cuja finalidade é ligar os indivíduos entre eles e à sociedade. Ou seja, são os vínculos entre os indivíduos que criam a família e são as variações possíveis desses vínculos intrafamiliares que caracterizam as formas possíveis de família.

São as regras estabelecidas
socialmente em cada lugar que determinam a "verdade" do parentesco, confirmando as afirmações de diversos antropólogos de que o parentesco é fundamentalmente um universo de vínculos genealógicos, simultaneamente biológicos e sociais (Cadoret, 2002; Godelier, 2005; Héritier, 2000). Não existindo um a priori de "verdadeira mãe" ou "verdadeiro pai", apenas uma decisão moral e social determinará a quais elementos da noção de família se dará prioridade em uma determinada sociedade (Parseval, 1998).

A Campanha \#MeuPaiPresente da Natura e a paternidade de Thammy

\section{Miranda}

Criada pela agência DPZ\&T, a campanha de Dia dos Pais 2020 da marca de cosméticos Natura trata do conceito \#MeuPaiPresente. Além do comercial na tevê, houve a escolha de alguns influenciadores que deveriam usar a hashtag \#MeuPaiPresente em suas redes sociais, promovendo reflexões sobre sua postura e o papel como pais na criação dos filhos.

A proposta da campanha, segundo a marca, além de enfatizar a paternidade ativa, tem como desafio "mergulhar na desafiadora rotina que todos estão vivendo durante a quarentena, mostrando como esse intenso convívio pode fortalecer a relação entre pais e filhos".

Nada de novo até que começassem as postagens por parte dos influenciadores. Assim que Thammy Miranda postou o vídeo com a hashtag \#MeuPaiPresente em seu Instagram, no dia 22 de julho de 2020, denotando que estava entre os influenciadores escolhidos 


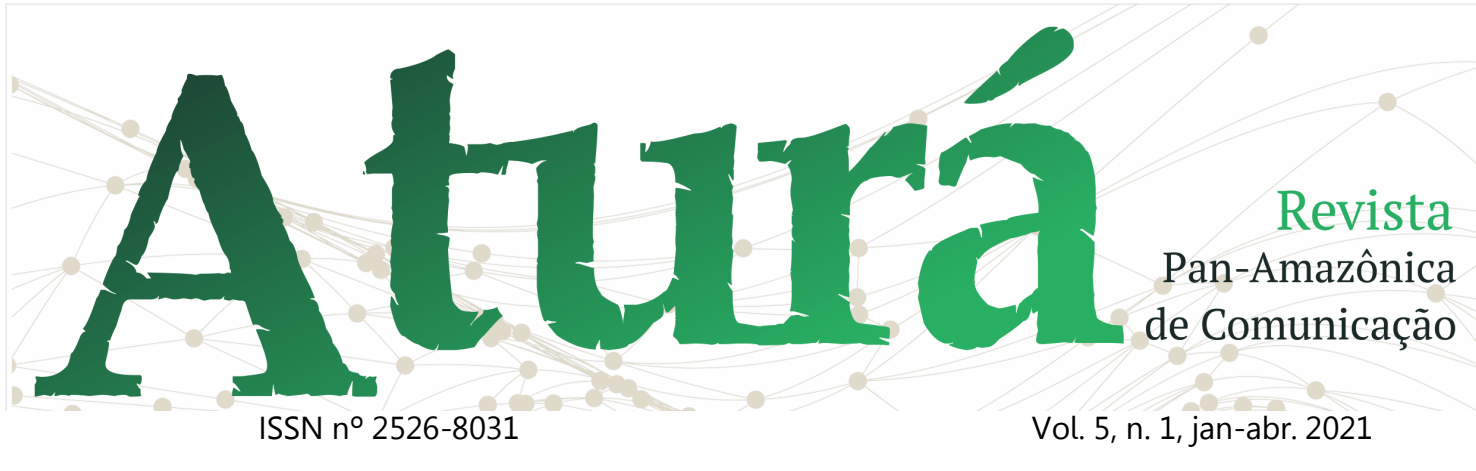

para estrelar a campanha, as redes sociais entraram em polvorosa e receberam muitos comentários sobre o assunto.

Enquanto muitas pessoas elogiaram a postura da Natura em incluir um homem transgênero na campanha, muitas outras criticaram a marca, chegando a propor um boicote à empresa. Ao longo de toda a semana até a segunda-feira, 27 de julho de 2020, o nome do ator Thammy Miranda e da marca Natura figuraram entre os assuntos mais comentados no Twitter. ${ }^{2}$

Figura 1: Postagem no Instagram de Thammy Miranda

\footnotetext{
2 Disponível em: < https://www.meioemensagem.com.br/home/comu nicacao/2020/07/28/natura-defende-thammy-etodas-as-maneiras-de-ser-homem.html>. Acesso em: 25 set. 2020.
}

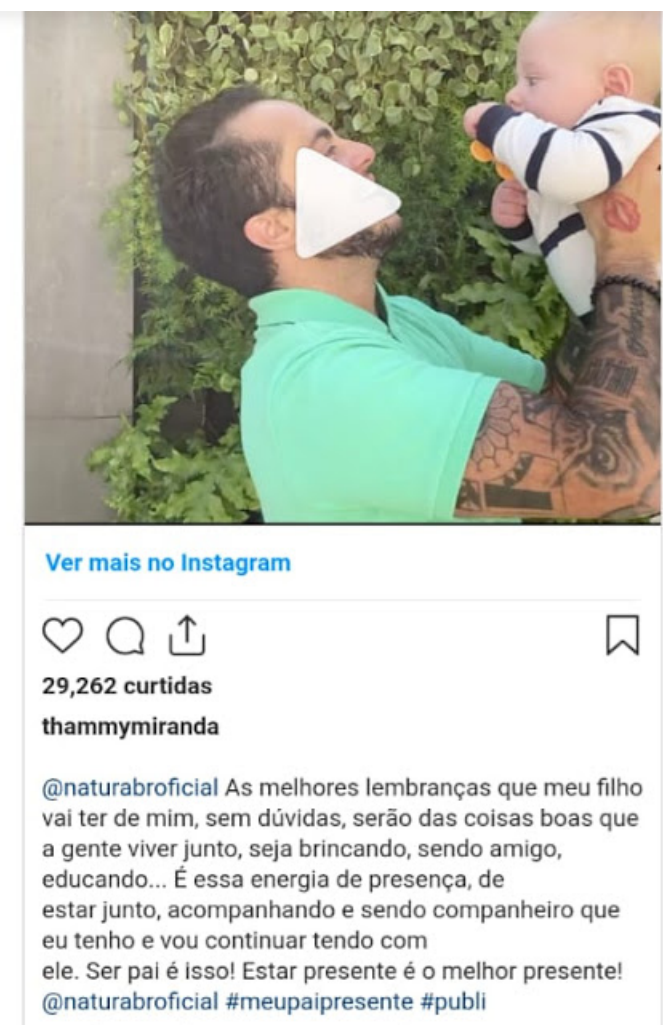

Fonte: Instagram @thamymiranda, 2020

Cabe ressaltar que, além de Thammy, também foram escolhidos para a campanha da Natura nomes como Babu Santana, Henrique Fogaça, Rafael Zulu e Família Quilombo. Logo, por qual motivo a presença de Thammy na campanha de Dia dos Pais de uma marca tão conhecida e consolidada em nosso país incomodou tanto? A resposta é simples: Thammy Miranda é um homem transgênero, 


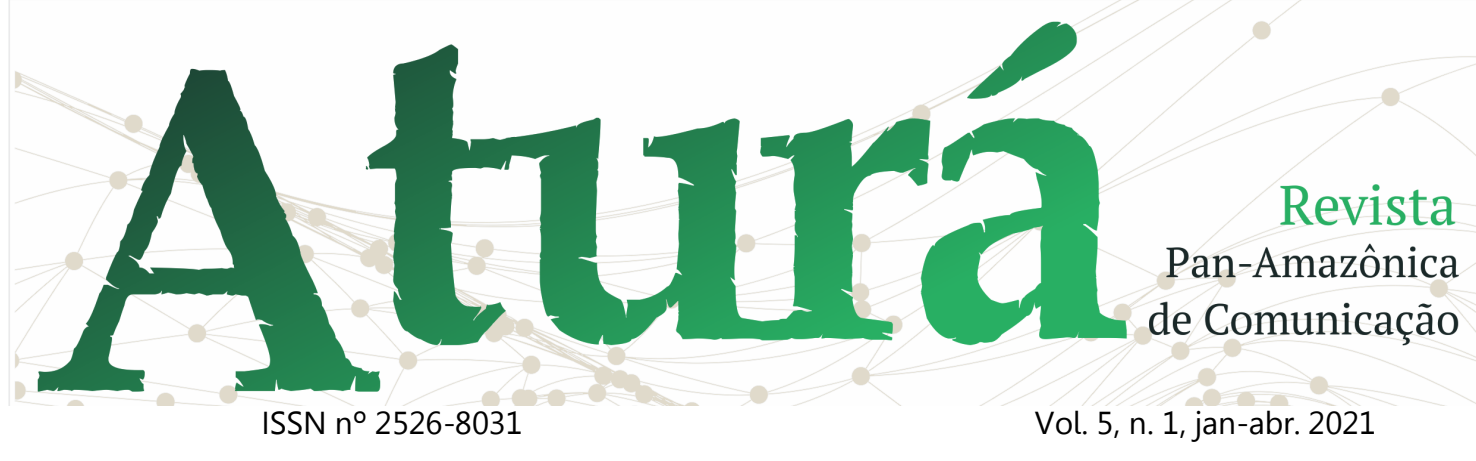

enquanto todos os outros mencionados na campanha são homens cisgêneros ${ }^{3}$.

Embora não devesse ser motivo de tamanho alvoroço, isso se deve ao fato de que vivemos em uma sociedade pautada na heteronormatividade e no determinismo biológico, que constituem o chamado "padrão". Ou seja, tudo aquilo que foge do "padrão", causa estranheza e repúdio por parte dos setores mais conservadores da sociedade.

Porém, não devemos esquecer que a diversidade existente em configurações familiares de outras sociedades permitenos afirmar que parentesco e filiação são sempre sociais (Héritier, 2000). Com isso, temos que eles não são apenas derivados da procriação, já que as regras adotadas por elas nem sempre serão a réplica exata da "natureza".

Ainda sobre o caráter social da família, Zambrano (2006) complementa:

Devido a essa variação dos papéis sociais parentais desempenhados nas diferentes culturas e períodos históricos, podemos,

\footnotetext{
${ }^{3}$ Conforme Pereira (2018, p. 30), cisgênero é a pessoa cujo gênero corresponde ao seu sexo biológico e transgênero é a pessoa cuja expressão ou identidade de gênero é diferente da atribuída em seu nascimento.
}

\begin{abstract}
também, compreender que parentalidade não é sinônimo de parentesco e filiação e pode ser exercida por pessoa sem vínculo legal ou de consanguinidade com a criança como ocorre, por exemplo, nas famílias recompostas, nas quais o cônjuge do pai ou da mãe participa cotidianamente da criação do filho.
\end{abstract}

Questionada por diversos veículos de imprensa, a Natura divulgou uma nota oficial ${ }^{4}$ onde reforça que celebra "todas as maneiras de ser homem":
"A Natura acredita na diversidade. Esse valor está expresso em nossas crenças há mais de vinte anos, estando sempre presente em nossas campanhas publicitárias e projetos patrocinados. A campanha de Dia dos Pais mergulha na rotina desafiadora que todos estão vivendo durante a quarentena e mostra como esse intenso convivio pode fortalecer a relação entre pais e filhos, mostrando que a presença paterna é o maior presente. A Natura celebra todas as maneiras de ser homem, livre de estereótipos e preconceitos, e acredita que essa masculinidade, quando encontra a paternidade, transforma relações".

\section{Repercussão da Presença de} Thammy Miranda na Campanha \#MeuPaiPresente na Mídia Digital

\footnotetext{
${ }^{4}$ Disponível em: < https://www.otempo.com.br/diversao/naturarebate-criticas-a-escolha-de-thammy-paracampanha-do-dia-dos-pais-1.2365307>. Acesso em: 15 set. 2020.
} 


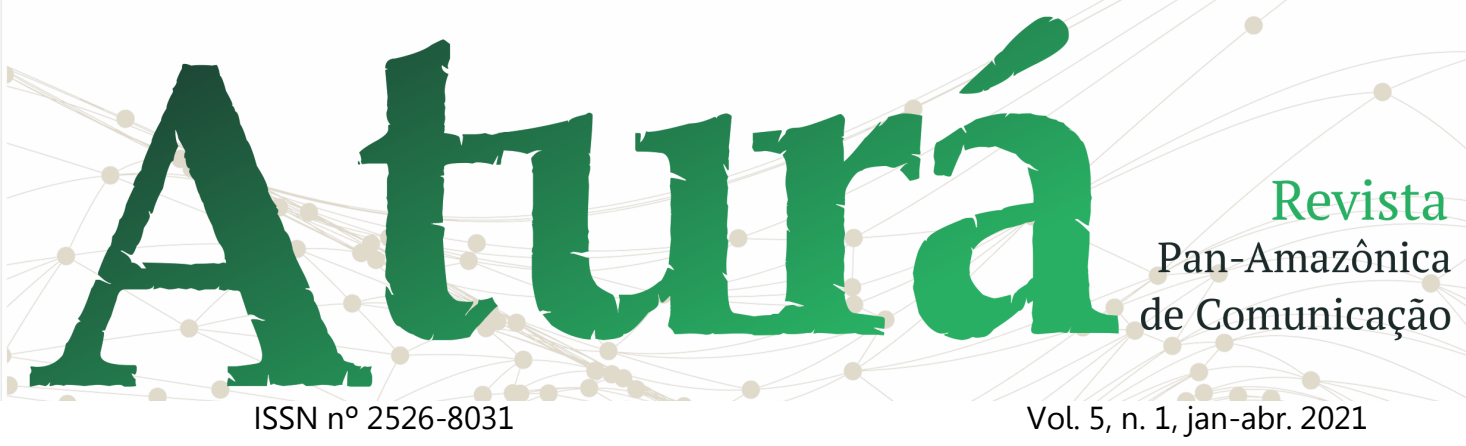

Muitas pessoas anônimas e
influenciadores saíram em apoio a Thammy Miranda com diversos comentários em suas redes sociais, dentre os quais ganharam destaque os comentários do ator Bruno Gagliasso e da advogada Gabriela Prioli. Escolhemos estes tweets pela relevância que possuem em relação com a história de vida pessoal de seus autores.

Sobre o tweet do ator Bruno Gagliasso, podemos verificar que no seu nome de usuário, ele já se autointitula "Pai de 3", o que reforça a questão da paternidade. Ao analisar rapidamente as informações sobre o ator e sua família em sites de busca, descobrimos que o ator e sua esposa, a atriz Giovanna Ewbank, são pais de duas crianças negras adotadas no Malawi, no sul da África, e de um filho biológico.

Imagem 2 - Tweet do ator Bruno Gagliasso
Bruno Gagliasso - Pai de $3 \curvearrowright$

@brunogagliasso

Fico assustado com a intolerância por que passa o Thammy e todas as pessoas trans do Brasil. Todo meu carinho aos que enfrentam diariamente essa batalha. - \#Tolerânciasim \#MaisAmor 6:05 PM $\cdot 28$ de jul de 2020

○ 11,8 mil $\bigcirc 67$ pessoas estão tweetando sobre isso

Fonte:Twitter@brunogagliasso, 2020

Com isso, temos uma família que, provavelmente pela empatia relacionada à sua configuração familiar "fora dos padrões", apoia Thammy e reconhece sua paternidade como legítima assim como compreende que a sua também deva ser (e que de fato é).

Sobre o tweet da advogada Gabriela Prioli, ele inicia com uma forte crítica ao "padrão": os homens cisgêneros heterossexuais. Claramente inconformada com o padrão existente na sociedade, ela faz questão de legitimar todos os pais, sejam eles cisgênero ou transgênero.

Imagem 3 - Tweet da advogada Gabriela Prioli 


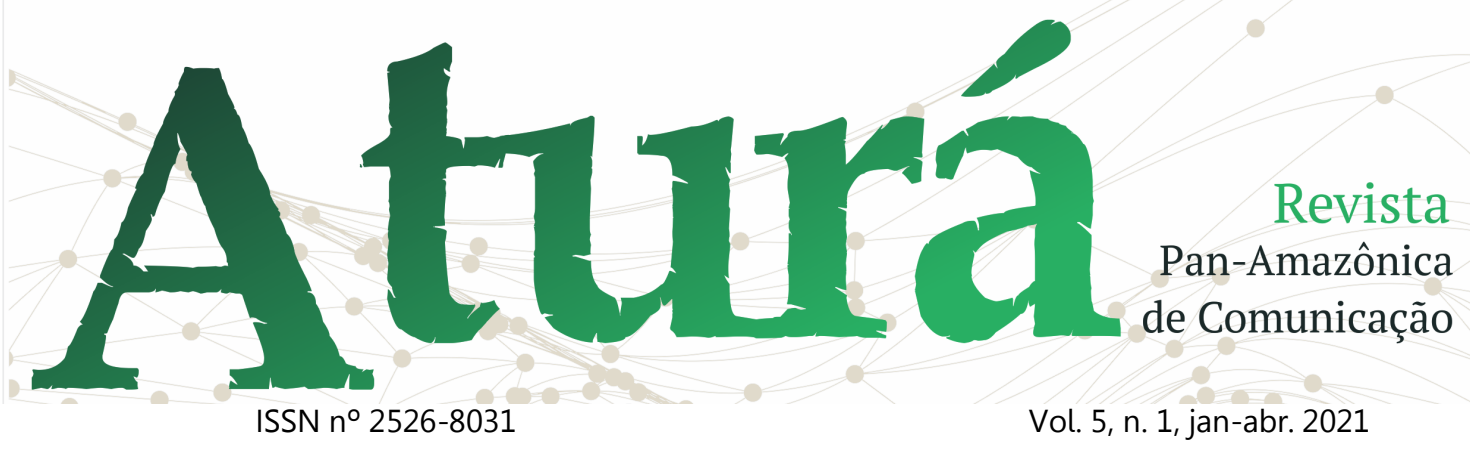

Gabriela Prioli

@GabrielaPrioli

Tantas crianças filhas de homens cis heterossexuais precisando de um pai como o@ThammyReal. Se todos os pais fosse como o Thanmy, não teríamos tantas mães solo, tantas crianças abandonadas. Tenham vergonha na cara.

8:26 PM · 27 de jul de 2020

29,6 mil $Q 3,6$ mil pessoas estão tweetando sobre isso

Fonte:Twitter@GabrielaPrioli, 2020

Fica claro em sua fala que não é isso que irá definir um "bom pai", e ainda cita Thammy Miranda como exemplo de um. Ainda, faz menção às crianças abandonadas por seus pais biológicos e às mães "solo", uma referência a mães solteiras, que por diversos motivos acabam criando seus filhos sozinhas. Termina com um claro recado aos transfóbicos de plantão: "Tenham vergonha na cara".

Ao buscar brevemente referências sobre a advogada, encontramos que ela é Mestre em Direito Penal pela USP, professora universitária, ativista feminista e apoiadora das causas LGBT. Inclusive, ficou conhecida por sua participação no programa da CNN Brasil "O Grande Debate, no qual fazia duras críticas ao governo Bolsonaro e a pautas preconceituosas e ultraconservadoras, ganhando fama de "jantar" ${ }^{5}$ seus convidados.

Assim como houve comentários de apoio, houve aqueles que criticaram duramente $\mathrm{o}$ fato de a Natura ter escolhido Thammy Miranda como um dos influenciadores a estrelar sua campanha de Dia dos Pais. Dentre estes, selecionamos dois que consideramos serem importantes não pelo tipo de comentário, mas pela representatividade que seus atores possuem: o do deputado federal pelo estado de São Paulo Eduardo Bolsonaro, filho do presidente da República Jair Messias Bolsonaro, e do pastor Silas Malafaia.

Ao iniciar a frase "Mulher como garoto propaganda do dia dos pais. Depois Homem para o Dia das Mães", o deputado Eduardo Bolsonaro demonstra todo seu ultraconservadorismo e

\footnotetext{
${ }^{5}$ Disponível em: < https://www.ocafezinho.com/2020/03/16/gabrielaprioli-janta-caio-coppola-em-debate-na-cnn-brasil/> . Acesso em 14 ago. 2020.
} 


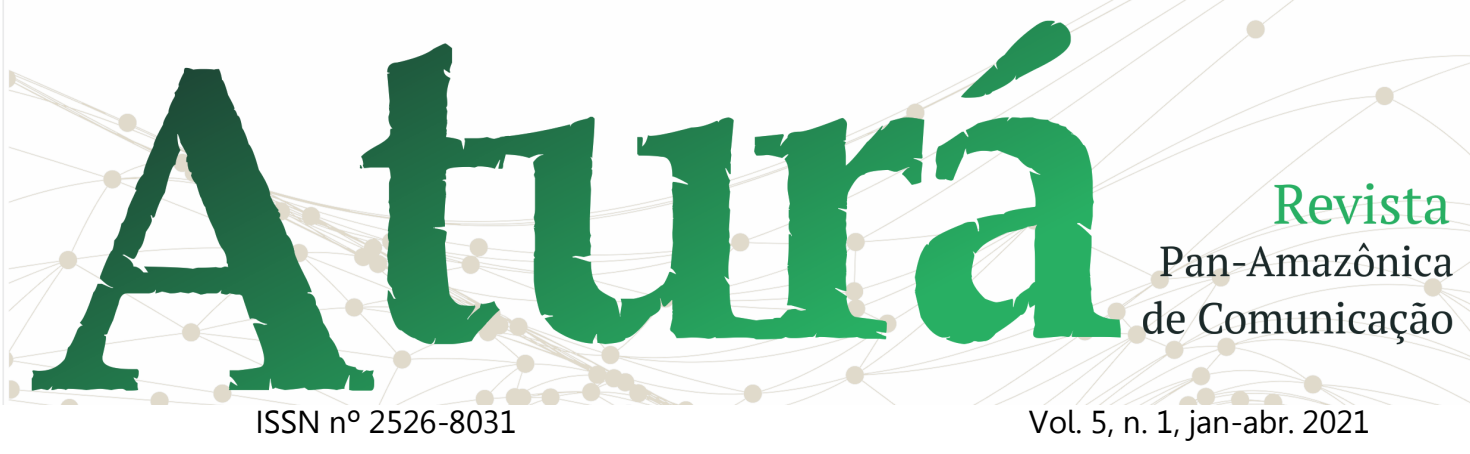

desconsideração com padrões que não sejam os biológicos

Imagem 4 - Tweet do deputado Eduardo

\section{Bolsonaro}

Eduardo Bolsonarole

@BolsonaroSP

Mulher como garoto propaganda do dia dos pais. Depois Homem para o dia das mães... E quem falar o contrário já sabe né? É gado, é pessoa raivosa, discurso do ódio e fake news.

Assim vão te calando e empurrando goela abaixo uma conduta totalmente atípica para padrões brasileiros. 8:33 AM . 28 de jul de 2020

○ 30,3 mil $Q 11$ mil pessoas estão tweetando sobre isso

Fonte:Twitter@BolsonaroSP, 2020

Butler (2011, p. 45) menciona que "o gênero não deve ser meramente concebido como a inscrição cultural de significado num sexo previamente dado, tem de designar também 0 aparato mesmo de produção mediante o qual os próprios sexos são estabelecidos". Logo, temos que o gênero é uma construção social e não estritamente biológica.

Devemos considerar também a polarização política do momento atual em nosso país. $O$ atual Presidente da República, Jair Messias Bolsonaro, possui um discurso extremamente

heteronormativo, machista, homo/transfóbico e ultraconservador ${ }^{6}$, que reflete diretamente nas ações da sociedade por meio daqueles que $\mathrm{o}$ elegeram. Seus filhos, seguidores da mesma linha de pensamento, propagam as mesmas ideias.

Já na fala "Assim vão te calando e empurrando goela abaixo uma conduta totalmente atípica para os padrões brasileiros", mais uma vez temos reforçada a ideia do "padrão" brasileiro: uma sociedade pautada na heteronormatividade e no determinismo biológico. A partir do momento que o deputado diz que esse seria o padrão brasileiro, ele invisibiliza e silencia todas as outras "condutas" que não fazem parte do "padrão", considerando que elas não existem ou não devam existir.

A fala do Pastor Silas Malafaia também expressa o inconformismo com a construção social do gênero, pois mesmo Thammy sendo um homem e se

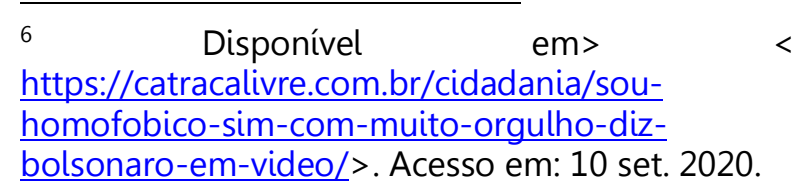




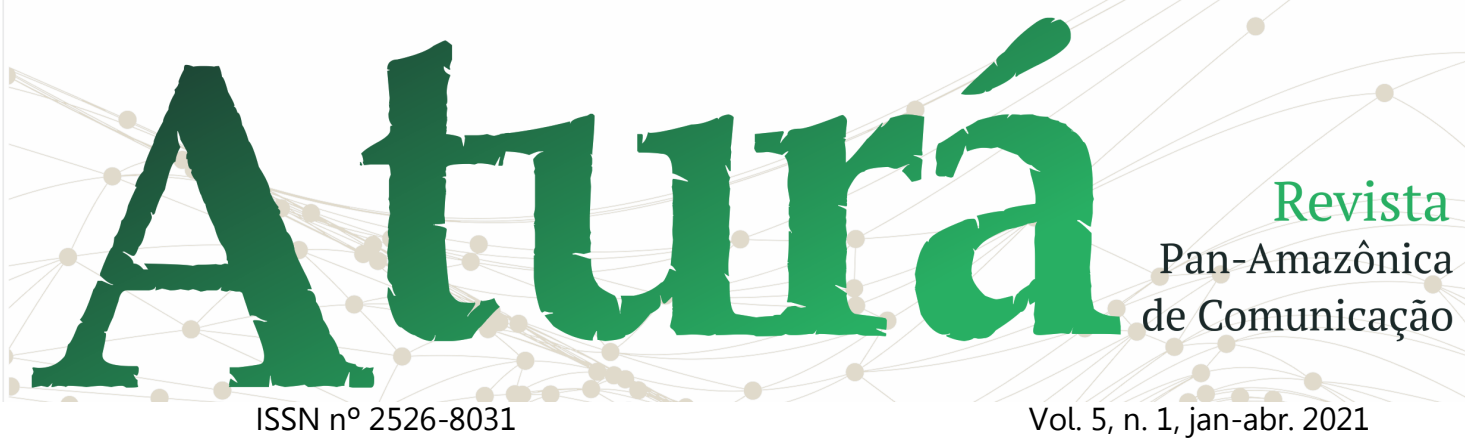

identificando como tal, o pastor insiste em tratá-lo por "mulher que faz papel de homem".

Imagem 4 - Tweet do pastor Silas Malafaia

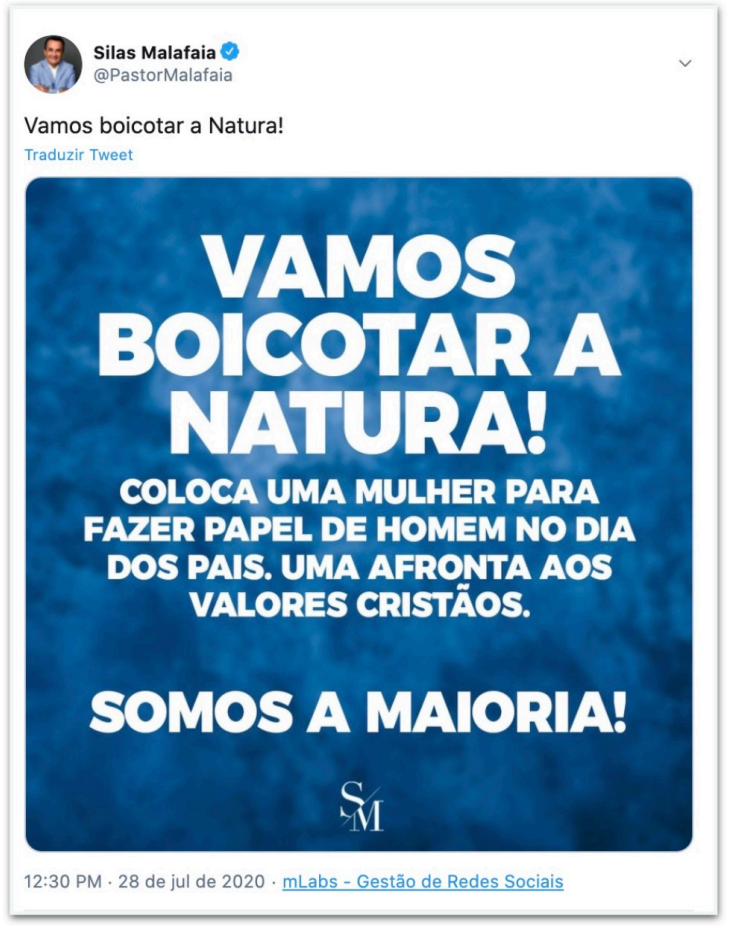

Fonte: Twitter@PastorMalafaia, 2020

Isso se deve possivelmente ao fato de que, em nossa cultura, imprime-se grande valor aos aspectos biológicos, muitas vezes sendo considerados como os únicos formadores dos vínculos familiares "verdadeiros". Entendem que o

pai precisa ter um pênis e que mulher precisa ter vagina para que possa ocorrer a fecundação de fato. Mas isso não necessariamente ocorre em outras configurações familiares, onde temos pais com vagina e mães com pênis, independente de gênero ou orientação sexual. É preciso considerar isso, pois é o reflexo da sociedade contemporânea.

Com o advento das novas tecnologias reprodutivas, - utilizadas inclusive por Thammy e sua esposa para gerar seu filho - quando se podem separar artificialmente os momentos naturalmente indivisíveis da fabricação de um ser humano: a fecundação, a gestação e o parto, até a "verdade" biológica incontestável da maternidade pode ser questionada (Godelier, 2005).

Já ao solicitar um "boicote" à empresa Natura com o argumento de que "somos a maioria", não fica claro quem seria maioria: a sociedade conservadora? Seus seguidores em redes sociais? Os fiéis de sua igreja? Seria um paralelo com a eleição de Jair Bolsonaro em 2018, que venceu em segundo turno 


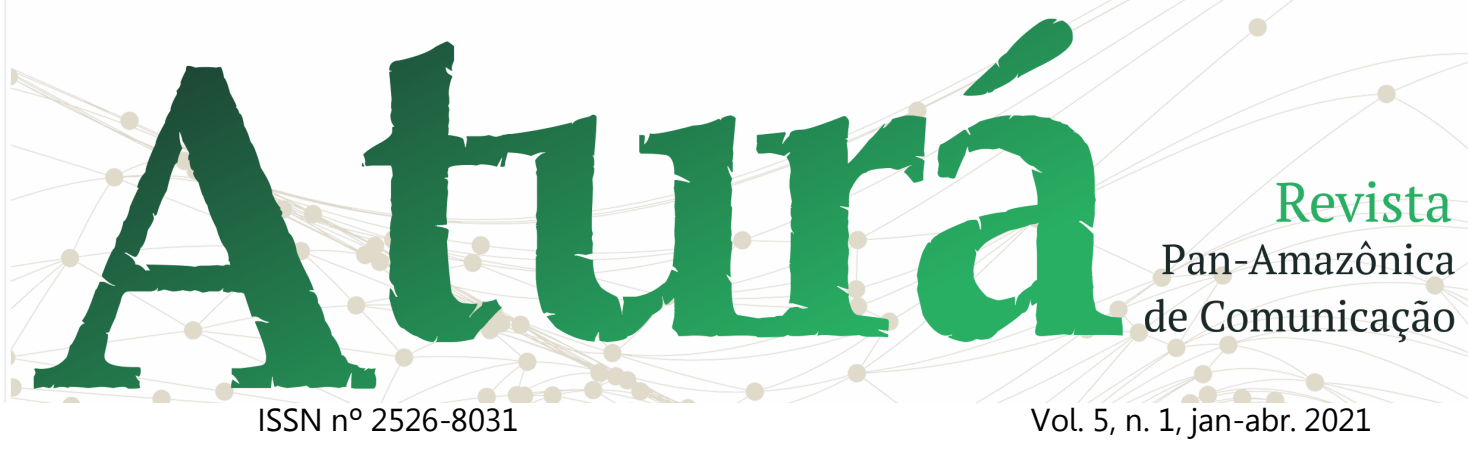

por maioria de votos? Enfim, qualquer que seja a resposta para essas perguntas, ainda assim não seria uma justificativa plausível para "maioria".

\section{Considerações Finais}

Este trabalho buscou analisar a representação masculina de Thammy Miranda em uma propaganda de Dia Dos Pais, de forma a refletir sobre as novas configurações familiares na sociedade e sobre o papel da mídia no processo de discussão acerca delas.

Demonstramos, inicialmente, com base na Teoria Queer de Judith Butler (2011), que pessoas trans carregam características que servem como marcadores essenciais de sua existência, revelando a construção social de sua identidade em contraponto com a binariedade de gênero, estritamente biológica. Ou seja, haverá mulheres com seios e pênis e homens de vagina.

Trouxemos, também, algumas contribuições da área do direito, onde pudemos verificar que a Constituição Federal de 1988 permite a configuração plural de família, considerando principalmente o caráter socioafetivo das relações. Alguns antropólogos e sociólogos (Ariés, 1981; Donzelot, 1986), mencionam que as configurações familiares vêm sofrendo alterações com o passar dos anos que devem ser levadas em conta. Lévi-Strauss (1976) complementa ao dizer que são os vínculos entre os indivíduos que criam a família e as variações possíveis desses vínculos intrafamiliares que caracterizam as formas possíveis de família, dando apoio à teoria de que a afetividade é tão importante quanto a questão de consanguinidade.

A grande repercussão desta campanha nas redes sociais mostra, conforme apontado por Pereira (2017), que "a interação viva trazida através da notícia e a consequente mobilização social denotam a grande influência que as redes sociais têm no processo opinativo das pessoas".

Verificamos que as manifestações de apoio partiram de pessoas empáticas e solidárias à causa, e que as 


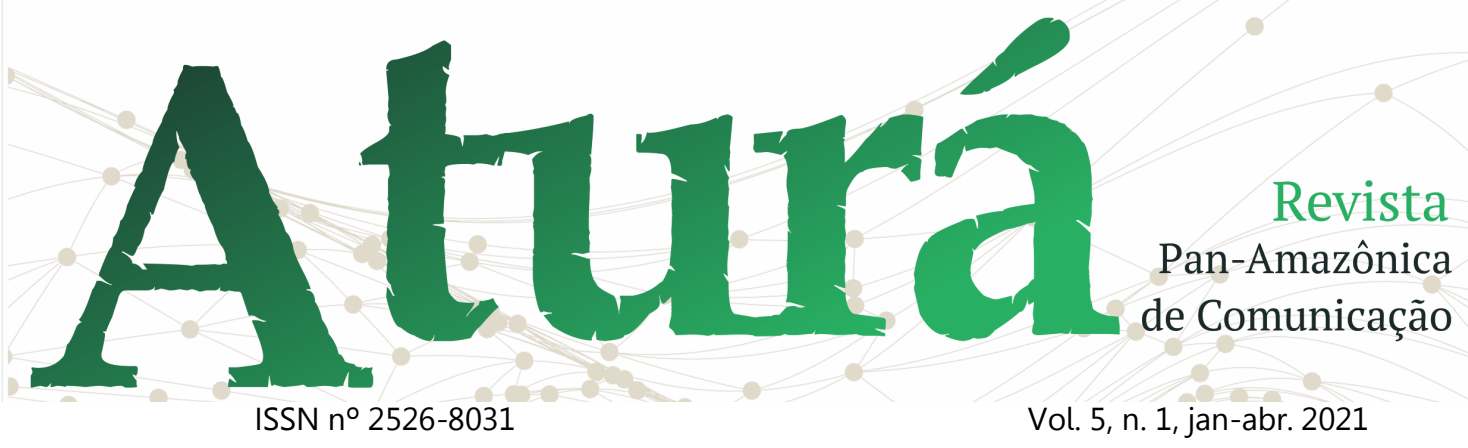

manifestações transfóbicas,

conforme visto nesse caso, seja para preconceituosas e de repúdio partiram de pessoas ultraconservadoras políticas e religiosas. Pudemos verificar, também, que para os apoiadores, a questão do gênero enquanto construção social é considerada, fato que é totalmente ignorado pelos críticos, que insistem no determinismo biológico para basear suas opiniões.

Pudemos compreender que tudo que envolve a transgeneridade na sociedade e que foge do chamado "padrão" ainda carrega consigo certo preconceito. Pereira (2017) menciona que "extingui-lo significa desconstruir a ideia de gênero como algo estritamente ligado ao sexo biológico, e tal desconstrução torna-se importante a partir do momento em que garante forte combate à discriminação".

Spink e Medrado (2004) propõem que a mídia é um poderoso meio de criação, de circulação e de transformação dos conteúdos simbólicos. E as redes sociais certamente têm um papel de grande importância neste sentido, apoiar ou criticar determinada pessoa ou marca.

Com isso, podemos concluir que a existência de diversos núcleos familiares, inclusive com transgêneros - ou (trans)parentais - são uma realidade no Brasil, devendo ser representados e legitimados, inclusive midiaticamente, sem tomar por base estereótipos e preconceitos.

\section{Referências}

ARIÉS, Philippe. História social da criança e da família. Rio de Janeiro: Guanabara, 1981.

BRASIL. Constituição 1988. Constituição da República Federativa do Brasil. São Paulo: Rideel, 2015.

BUTLER, Judith. Problemas de Gênero: feminismo e subversão da identidade. Rio de Janeiro: Civilização Brasileira, 2011.

ADORET, Anne. Des parents comme les autres. homosexulité et parenté. Paris: Odile Jacob, 2002.

CARVALHO, Diana. "Campanha valoriza pais presentes. Thammy é um", diz executiva da Natura. Disponível em: <https://www.uol.com.br/ecoa/ultimasnoticias/2020/07/31/campanha-valoriza- 


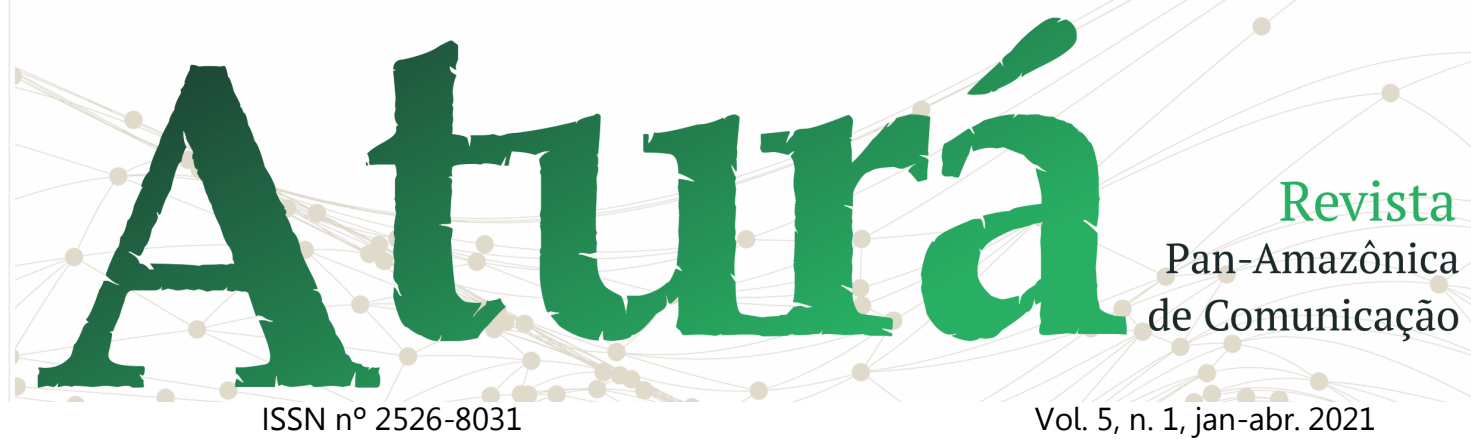

pais-presentes-thammy-e-um-dizexecutiva-da-natura.htm >. Acesso em: 15 set. 2020.

CASTRO, Aline. TRAVESTI É RESISTIR: lutas, microlutas e resistência nas tirinhas de Muriel. 2017. 179 f. Dissertação (Mestrado em Comunicação) - Programa de Pós Graduação em Comunicação, Universidade Paulista, São Paulo. 2017.

DIAS, Maria Berenice. Violência doméstica $\boldsymbol{e}$ as uniões homoafetivas. Jus navegandis, Teresina, 2006.

DONZELOT, Jacques. A polícia das famílias. Rio de Janeiro: Graal, 1986.

ESTADÃO CONTEÚDO. Caso de Thammy Miranda dá visibilidade para pais trans. Disponível em $<$ https://exame.com/casual/thammymiranda-e-a-espera-feliz-e-normal-pelodia-dos-pais/>. Acesso em: 10 ago. 2020.

GODELIER, Maurice. Métamorphoses de la parenté. Paris: Fayard, 2005.

GUIMARÃES, C. D. O Homossexualismo Visto por Entendidos. Rio de Janeiro: Garamont, 2004.

HÉRITIER, Françoise. A coxa de Júpiter. Revista Estudos Feministas, Florianópolis: CFH/UFSC, v. 8, n. 1, p. 98114, 2000.

LÉVI-STRAUSS, Claude. As estruturas elementares do parentesco. Petrópolis: Vozes, 1976.

NATURA. Dia dos Pais Natura: \#MeuPaiPresente. 2020. (1m00s). Disponível em: < https://www.youtube.com/watch?v=w8A Qe9jop8Y\&feature =emb_title $>$. Acesso em: 02 set. 2020.

NOGUEIRA, Conceição. Contribuiç̧̃es do Construcionismo Social a uma nova psicologia do gênero. Cadernos de Pesquisa. Março, $n^{\circ} 12$, 2001b, pp. 137154.

PEREIRA, Raphaella Freitas Petkovic de Carvalho. Os Casos Verônica Bolina e Marianna Lively: Análise de Enunciados da Folha de S. Paulo sobre Identidades Trans nas Mídias Digitais. In: XI Encontro Nacional de História da Mídia - ALCAR, 2017, São Paulo. Anais (on-line). Disponível em:

file:///C:/Users/Raphaella\%20Petkovic/Do wnloads/gthistoriadamidiadigital raphaell a freitas petkovic de carvalho pereira\%2 0-1\%20(4).pdf. Acesso em: 15 set. 2020.

PEREIRA, Raphaella Freitas Petkovic de Carvalho. O Universo Trans e a Mídia Digital: Visibilidades e Invisibilidades nas Olimpíadas Rio 2016. São Paulo: Pimenta Cultural. 2020.

PORTILHO, Silvia de Abreu Andrade; REZENDE, Graciele Silva. União homoafetiva como modelo de família no Brasil. Revista Jus Navigandi, ISSN 15184862, Teresina, ano 23, n. 5420, 4 maio 2018 . Disponível em: <https://jus.com.br/artigos/65879>. Acesso em: 01 out. 2020. 


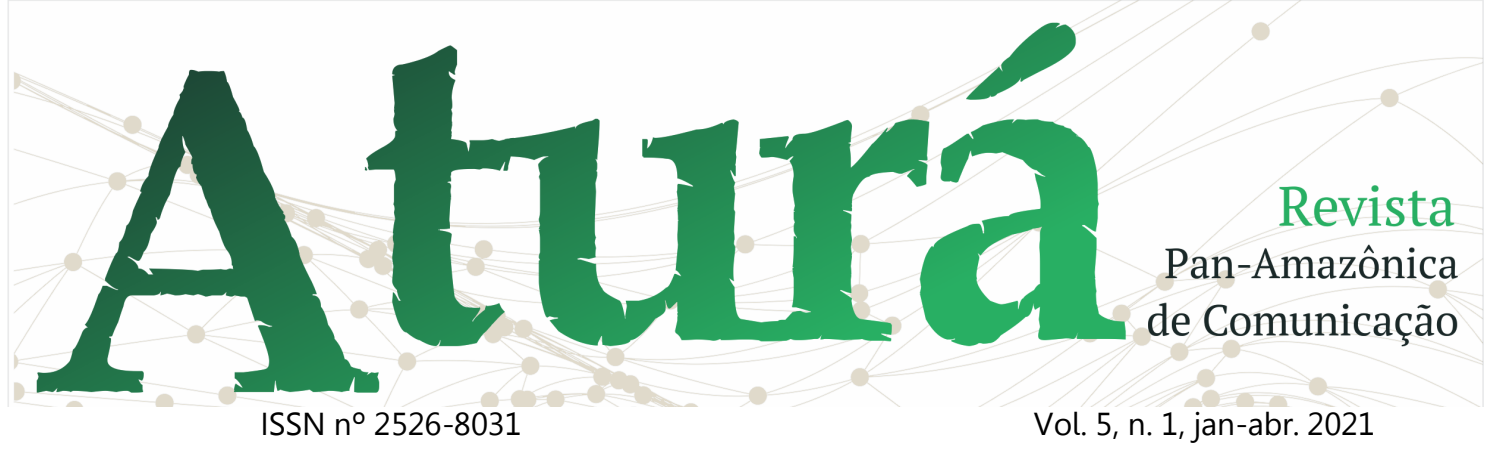

PUTTI, Alexandre. A "opinião" criminosa dos bolsonaristas no caso do Thammy Miranda. Disponível em < https://www.cartacapital.com.br/diversida de/a-opiniao-criminosa-dosbolsonaristas-no-caso-do-thammymiranda/>. Acesso em: 03 ago. 2020.

SPINK, Mary Jane; MEDRADO, Benedito. Produção de sentidos no cotidiano: uma abordagem teórico-metodológica para análise das práticas discursivas. In.: SPINK, Mary Jane (Org.). Práticas discursivas e produção de sentidos no cotidiano: aproximações teóricas e metodológicas. $3^{\mathrm{a}}$ ed. - São Paulo: Cortez, 2004.

ZAMBRANO, Elizabeth. Parentalidades "impensáveis": pais/mães homossexuais, travestis e transexuais. Horiz. antropol., Porto Alegre, v. 12, n. 26, p. 123-147, Dec. 2006 . Disponível em: <http://www.scielo.br/scielo.php?script=s ci_arttext\&pid=S0104$71832006000200006 \& \operatorname{lng}=$ en\&nrm $=$ iso $>$. Acesso em: 10 set. 2020. 